\title{
Assessment of weight reduction in overweight adult people with combination treatment of electronic devices, diet and physical exercise
}

\author{
N. PALIWAL AND G. BABEL
}

Received: 11.01.2017; Revised: 17.03.2017; Accepted: 03.04.2017

See end of the paper for authors' affiliations

\section{N. PALIWAL}

Department of Home Science, College of Social Sciences and Humanities, Mohan Lal Sukhadiya University, UDAIPUR (RAJASTHAN) INDIA

Email : niharikapaliwal9928@ gmail.com
ABSTRACT : Obesity is a public health problem that has raised concern worldwide. According to the World Health Organization (WHO), there will be about 2.3 billion overweight people aged 15 years and above, and over 700 million obese people worldwide in 2015. This study was conducted assess weight reduction in overweight adult people with combination treatment of electronic devices, diet and physical exercise. All available subjects attending a commercial weight reduction clinic were selected. The sample comprised one hundred eighty adult (180) peoples (90 male and 90 female) in the age group of 30-40 year. We aimed to examine the effectiveness of combined nutrition and complete lifestyle modification package (NCLMP) for overweight adult people. In NCLMP we combined electronic Devices, diet and physical exercise programmes with at least 6 months of follow-up, conducted in overweight and obese adults (body mass index $\geq 25$ ). Results revealed that in Pre-intervention phase majority of the subjects $(75 \%)$ were found to be in the category of high risk while minority of the respondents $(25 \%)$ had normal WHR $(<0.8)$. The mean WHR was $0.83 \pm 0.0$. and the fat values exceed the normal range of fat, diet of subjects in comparison to the balanced diet was substantially inadequate in food groups, representing the excess fat deposition in the subjects owing to obesity. Intervention phase results revealed effect of electronic devices, physical exercise and nutritionally balanced weight loss diet on body composition of males were showed body fat $(\%)$ before intervention

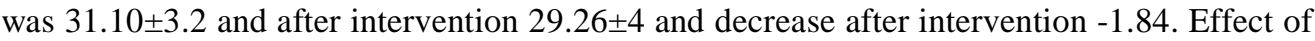
electronic devices, physical exercise and nutritionally balanced weight loss diet intervention on body composition of females were found body fat (\%) before intervention was $33.83 \pm 4.6$ and after intervention 32.2 \pm 4.5 and decrease after intervention -1.59. Weight loss is similar in the short-term for diet-only but with combined longer-term programme weight loss is increased when electronic devices, diet and physical activity are combined.

KEY WORDS: Adult, Overweight, Body mass index (BMI), Waist hip ratio (WHR), Balanced diet, Nutritional status

- HOW TO CITE THIS PAPER : Paliwal, N. and Babel, G. (2017). Assessment of weight reduction in overweight adult people with combination treatment of electronic devices, diet and physical exercise. Asian J. Home Sci., 12 (1) : 8-17, DOI: 10.15740/HAS/AJHS/12.1/8-17. 